\title{
A Novel Approach for Measuring the Thickness of Refractory of Metallurgical Vessels
}

\author{
Yao Ge, Ying Li, Han Wei, Hao Nie, Weitian Ding, Yi Cao and Yaowei Yu *
}

State Key Laboratory of Advanced Special Steel, Shanghai Key Laboratory of Advanced Ferrometallurgy and the Science and Technology Commission of Shanghai Municipality, School of Materials Science and Engineering, Shanghai University, Shanghai 200444, China; ge_geyao@hotmail.com (Y.G.); yingli9104@163.com (Y.L.); weihan@shu.edu.cn (H.W.); niehao@shu.edu.cn (H.N.); dingweitian@shu.edu.cn (W.D.); 13166255603@163.com (Y.C.)

* Correspondence: yaowei.yu@hotmail.com

Received: 11 November 2020; Accepted: 7 December 2020; Published: 10 December 2020

\begin{abstract}
The advancement of metallurgical vessels, such as blast furnaces, shaft furnaces, and torpedo ladles, can be better controlled and expanded for a greater lifespan if the thickness of the refractory lining wear is known and predicted. In the past, various methods including radioactive tracers, infrared (IR) thermography, electromagnetic waves, ultrasonic tomography, and temperature field have been tested to determine the thickness of the refractory wall. However, for various reasons, these methods have failed to be effective. This paper presents a novel method-electromotive force (EMF)—for predicting the thickness of refractory lining wear in vessels, including a small-scale vessel in the laboratory, an industrial torpedo ladle, and in the two refining hearths of blast furnaces. The experimental results show that the magnitude of the EMF signal increases with a decrease in wall thickness. Prediction values of the refractory wall thickness are consistent with measured ones. The relative error of EMF measurement for the torpedo ladle is around $6.8 \%$. The EMF measurement of blast furnace hearths is quite accurate, and the relative error is less than $11 \%$.
\end{abstract}

Keywords: blast furnace monitoring; refractory thickness; vessel campaign; electromotive force; hearth campaign

\section{Introduction}

Refractory materials are designed to remain physically and chemically stable under high-temperature conditions and are used for the linings of furnaces [1], kilns, ladles [2], reactors, converters, and other types of high-temperature vessels [3,4]. For instance, blast furnace hearths are lined with graphite, ramming material, ceramics, and carbon bricks [5] from the core to the periphery. Fracturing, damage, corrosion, and deeper deterioration of the hearth refractory are caused mainly by mechanical and thermal stress cracks, and chemical attacks which result in the loss of heat transfer capability, shrinkage, and a change in thermal conductivity of the refractories [6-8]. Furthermore, a sudden shutdown of the blast furnace [9] causes a loss in the production of hot metal and shortens the lifespan of the refractory materials. Therefore, the hearth advancement may be better controlled if the thickness of the refractory material can be measured accurately.

In the past, varying approaches have been proposed to detect and measure the thickness of hearth linings [10]. Short half-life radioactive tracers dumped at the top of the furnace have been used to detect the thickness of linings [11-13]. The failure in the tracer method is that the hearth linings of blast furnaces are nonuniform and refractories with different densities and material properties are utilized in the lining. IR thermography has been considered as a method to measure hearth lining wear. However, steel shell oxidization affects the surface emissivity which results in inaccuracies in the IR thermograph 
measurements [13]. By detecting electromagnetic waves, such as microwaves [14] and radar, refractory thickness can be determined. However, electromagnetic waves cannot pass through the steel shell and enter the lining. In the late 1990s, Ultrasonic tomography (UT) and acoustic ultrasonic-echo (AU-E) techniques developed by the Hatch NDT Group were also tested to measure refractory thickness wear $[15,16]$. However, the stress pulses in AU-E and waves in UT increased the measurement error twice by the "go" and "return" routes of signal transmission. Analysis of temperature distribution by thermocouples and heat fluxes in refractory lining is a rudimentary technique that has been used to determine the refractory wear profile in furnaces [17], and was validated by dissection data at the end of more than a 10-year period $[18,19]$. In recent years, scientists proposed a variety of erosion mathematical models and expert systems $[20,21]$ to estimate the profile of the erosion by the thermocouple's data. These mathematical models are based on heat conduction in solid material by measuring the temperatures of the thermocouples in the refractories [22]. Therefore, the coefficient of heat conductivity of refractories is dependent on the temperature and directly affects the model results.

In the present work, a novel method of electromotive force (EMF) technology based on the thermoelectric effect is proposed for the first time to measure the thicknesses of refractory wear at the laboratory and plant scales.

\section{Experimental Methods}

In order to apply the EMF technology to the measurement of thicknesses of refractory wear, three experiments were designed. Laboratory scale experiments, first, were completed on two graphite crucibles where EMF sensors were installed in the different locations of the vessel. Second, a torpedo ladle experiment was performed on the torpedo ladle of a steel plant where EMF sensors were installed in the air exhausting holes of the shell. Third, the blast furnace hearth experiments were carried out using a new blast furnace.

\subsection{Experimental Apparatus and Procedure of Laboratory Scale Experiment}

The laboratory scale experimental apparatus was composed of refractory mortar and two graphite crucibles as shown in Figure 1, where the iron lines are EMF sensors and thick bolts are inserted in the wall of the crucible to stabilize the thin molybdenum alloy lines around the circumference of the vessel.

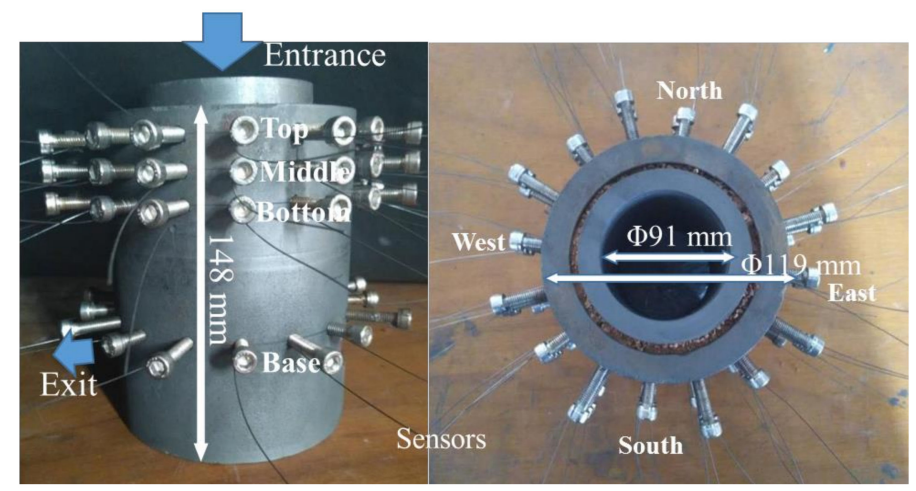

Figure 1. Schematic diagram of a laboratory vessel mimicking blast furnace hearth (left: front view, right: top view, and thin molybdenum alloy lines: electromotive force (EMF) sensors).

The three scenarios of the laboratory vessel used to simulate the erosions of hearth wear are presented in Figure 2. Figure 2a illustrates three arcs with different heights $(5,10$, and $15 \mathrm{~mm})$ made by the aluminum oxide. The arcs were inserted and fixed along the inner wall at the bottom of the vessel before the experiments were performed. Another new vessel had four thicknesses $(5,10,15$, and $20 \mathrm{~mm}$ ) at different points along the circumference, which can be seen in Figure 2b. EMF sensors were fixed at five depths $(24,19,14,9$, and $4 \mathrm{~mm})$ in a hole on the wall of the vessel as shown in Figure 2c, and they were used to measure the effect of EMF signals on the thickness of the wall. 

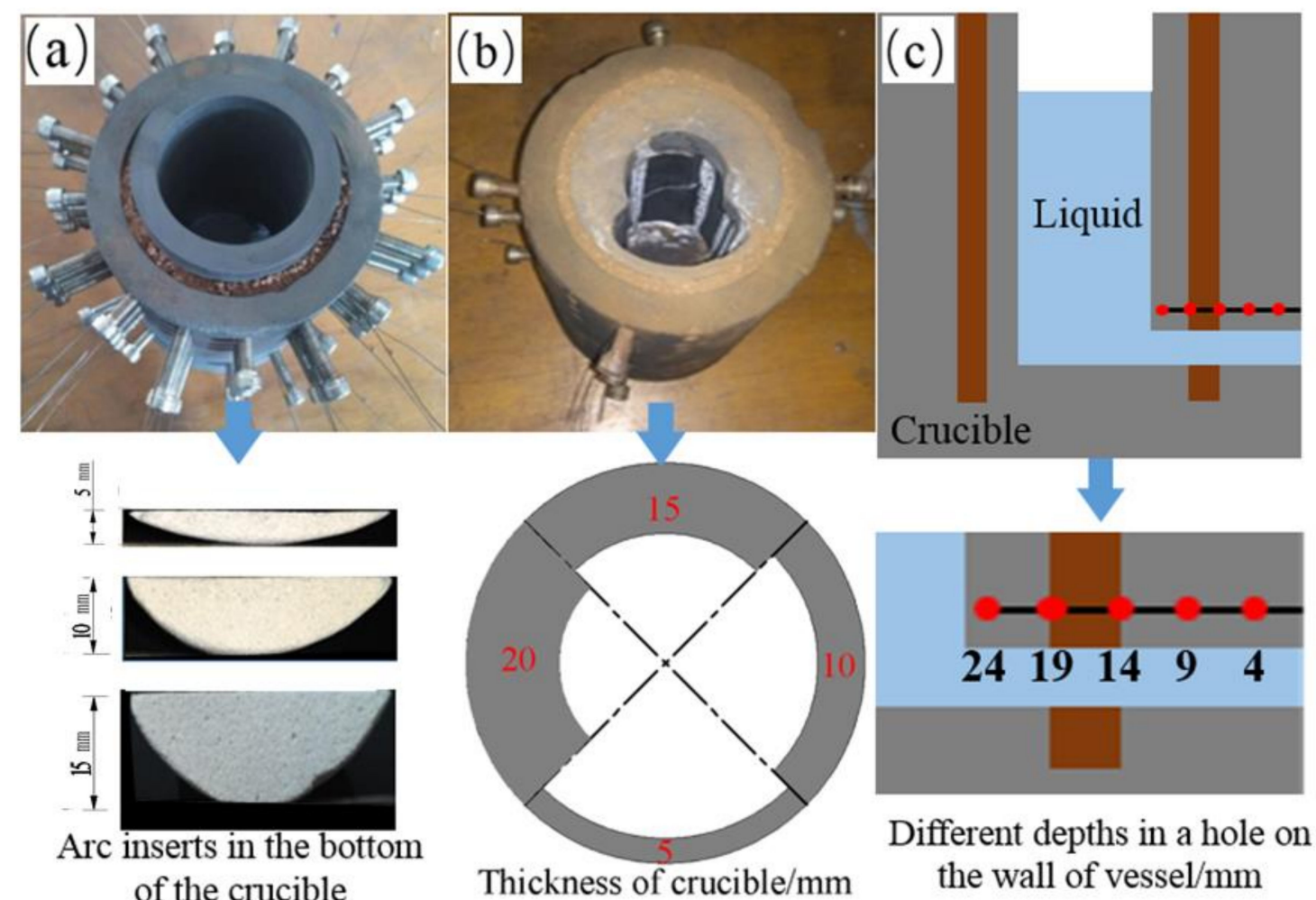

Figure 2. Three scenarios for crucible erosions of the laboratory vessel: (a) three arc inserts, (b) four different thicknesses along the circumference, and (c) different depths $(24,19,14,9$, and $4 \mathrm{~mm}$ ) in a hole on the wall of the vessel).

At the beginning of the experiments, around $5 \mathrm{~kg}$ of liquid tin was dumped into the apparatus from the entrance as shown in Figure 1. Then, the tin flowed out with the gravitational force from the exit at the bottom of the vessel. During the drainage of the liquid metal, the measurement system shown in Figure 3 includes the EMF sensors, the signal transform, the signal visualization, and a laptop that recorded the EMF signals.

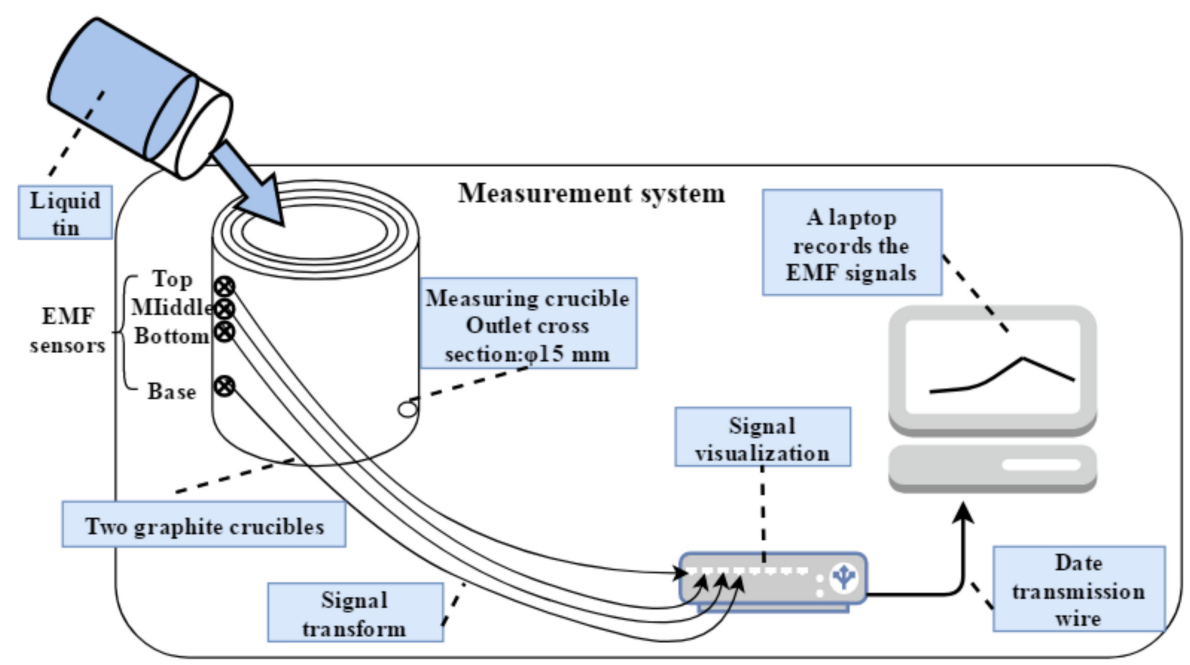

Figure 3. The EMF measurement system from the laboratory. 
A relative value of the $\operatorname{EMF}(\triangle \mathrm{EMF}[9,23])$ was calculated by the difference between the signals at various heights and the basic value at the bottom of the vessel:

$$
\Delta \mathrm{EMF}=\mathrm{EMF}_{\text {base }}-\mathrm{EMF}_{\text {top,middle or bottom }}
$$

\subsection{Experimental Apparatus and Procedure of Industrial Torpedo Ladle Experiments}

In order to validate the new approach, a $285 \mathrm{t}$ torpedo ladle was used in the industrial experiment to measure the thickness of the refractory lining wear by EMF signals for 3 days. The refractory properties of the torpedo ladle wall, the locations, and the depth of EMF sensors are shown in Figure 4A, where the "a" has two sensors at 32 and $44 \mathrm{~mm}$ depths, respectively, and the depth of the other sensors is $32 \mathrm{~mm}$. All sensors were fixed in pyrophyllite brick by bolts. The designed thickness of each layer in the torpedo ladle is shown in Figure 4B.

Before the torpedo ladle experiment, the torpedo ladle first arrived at the hot-metal receiving position under the cast house. Then, during the process of receiving the hot metal, the torpedo ladle measurement system, like the one in Figure 3, was installed to collect EMF signals.
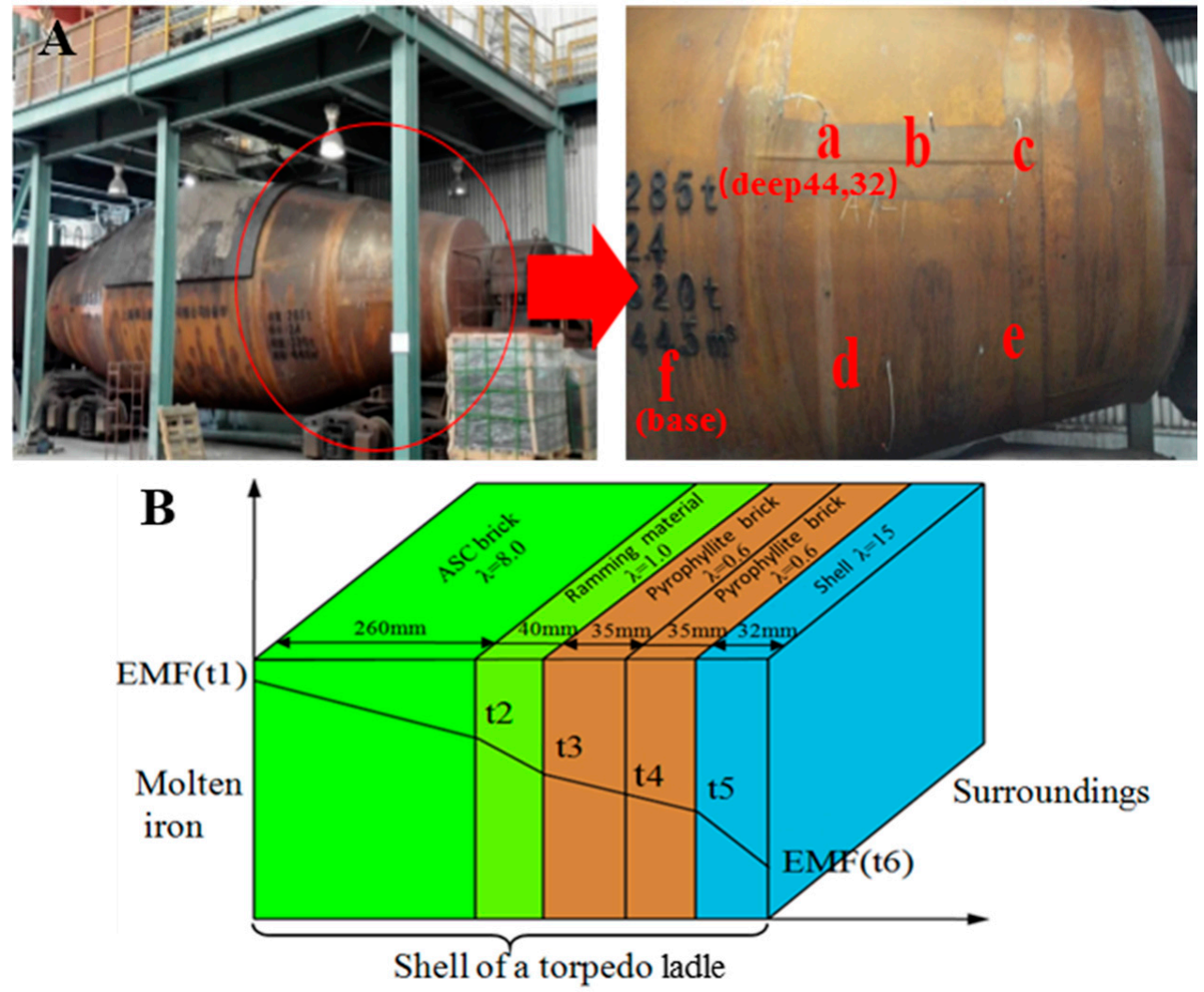

Figure 4. EMF experiments and sensor locations in the shell of a $285 \mathrm{t}$ torpedo ladle: (A) EMF locations of $a, b, c, d, e$, and $f$ on the shell and (B) properties of each refractory layer from $\mathrm{Al}_{2} \mathrm{O}_{3}-\mathrm{SiC}-\mathrm{C}$ (ASC) brick to steel shell).

Relative EMF signals from the different measurement locations on the torpedo ladle were calculated with Equation (2):

$$
\Delta \mathrm{EMF}=\mathrm{EMF}_{\text {base }}-\mathrm{EMF}_{\text {deep } 34 \text { or } 44}
$$

\subsection{Experimental Apparatus and Procedure of Industrial Blast Furnace Hearth}

The EMF method was also applied to the new hearth of a blast furnace with $2000 \mathrm{~m}^{3}$ volume, where an industrial experiment was performed to measure the thickness of refractory wall. 
An EMF measurement system was designed according to the structural characteristics of the blast furnace's hearth and the experiments in the previous laboratory and torpedo ladle. It included an EMF sensor, compensation wire, junction box (installed on the blast furnace shell), wiring bridge, signal converter, and a display device as shown in Figure 5. The sensors contained molybdenum wire (the core), silicon dioxide material for insulation, and inconel material for protection (the surface). The EMF sensors, made of molybdenum alloy wire, were buried into the graphite brick during construction of the hearth of the furnace as shown in Figure 6. They were inserted at three different depths in the refractory via a hole along two directions of the hearth at 8494, 9494, and 10,994 mm, respectively (see Figure 7). In order to form a close circuit [23-25] in the hearth, a reference point was chosen at the level of 6394 as shown in Figure 7. The wires of the EMF sensors sent the signal to the junction box. The compensation wire connected the junction box and the signal converter through the wiring bridge on the blast furnace platform. Finally, the signals of EMF were displayed on the monitor in the main control room of the blast furnace operation.

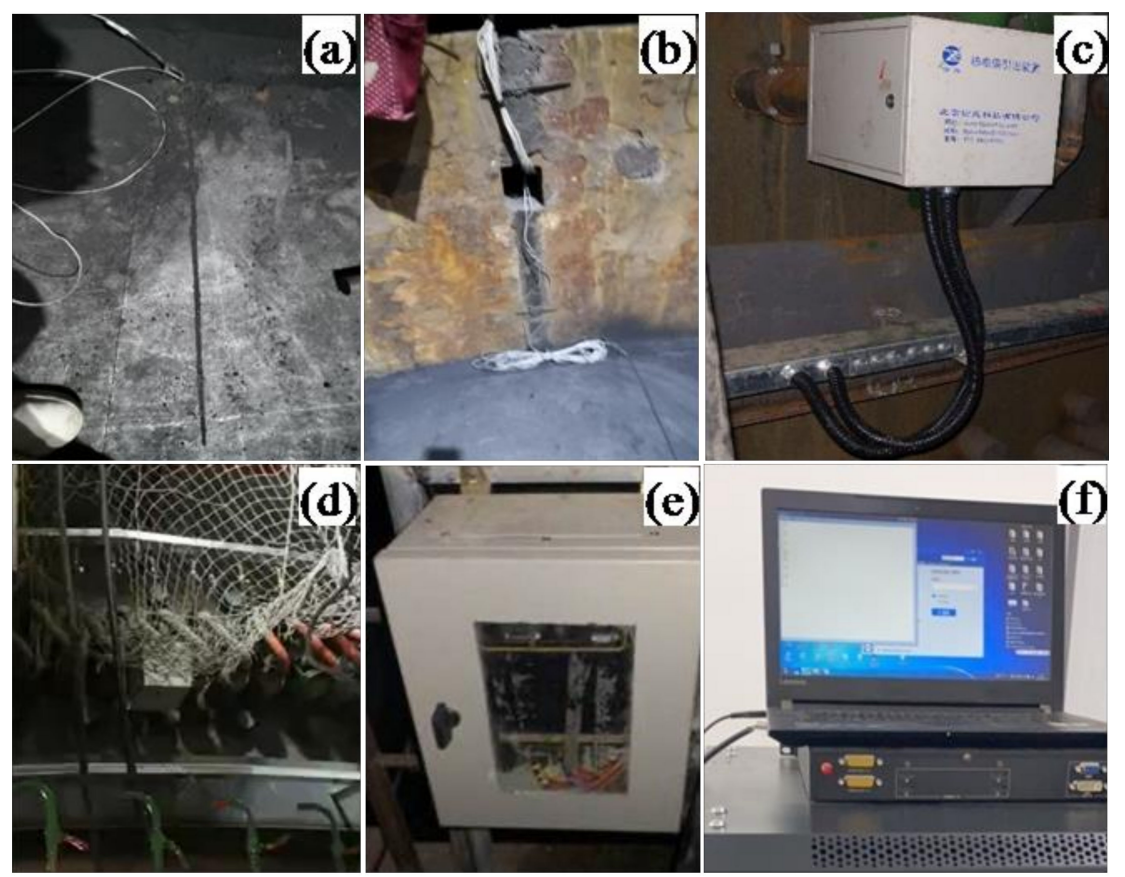

Figure 5. EMF measurement system on the blast furnace hearth: (a) EMF sensor, (b) compensation wire, (c) junction box, (d) wiring bridge (e) signal conversion box, and (f) display device.

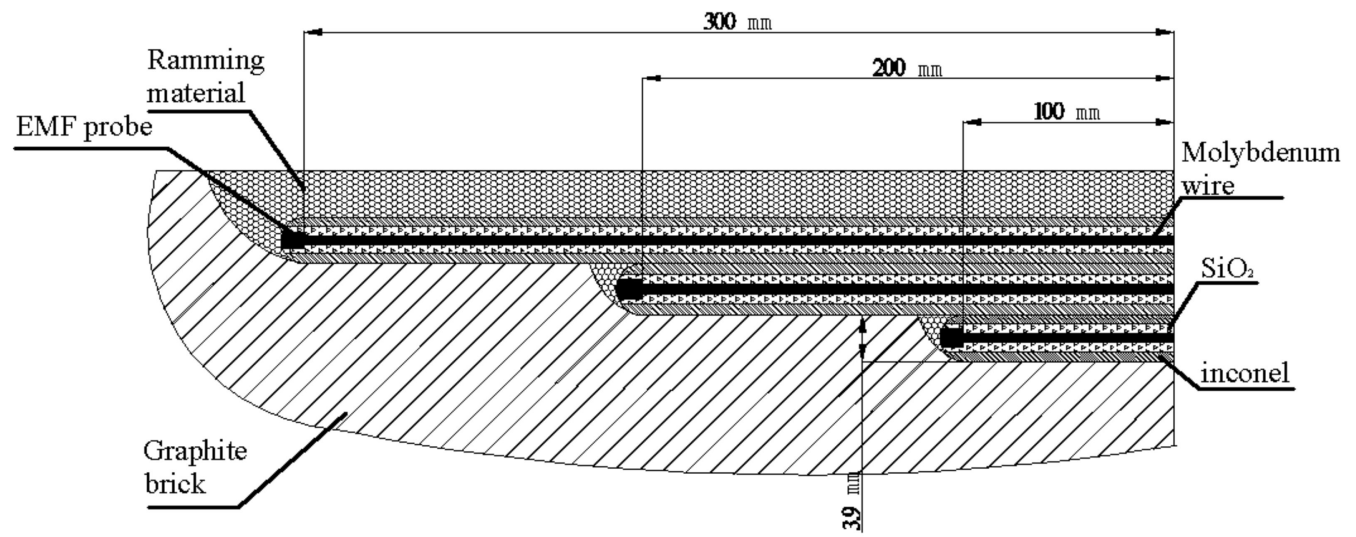

Figure 6. Three EMF sensors in a hole of graphite brick. 


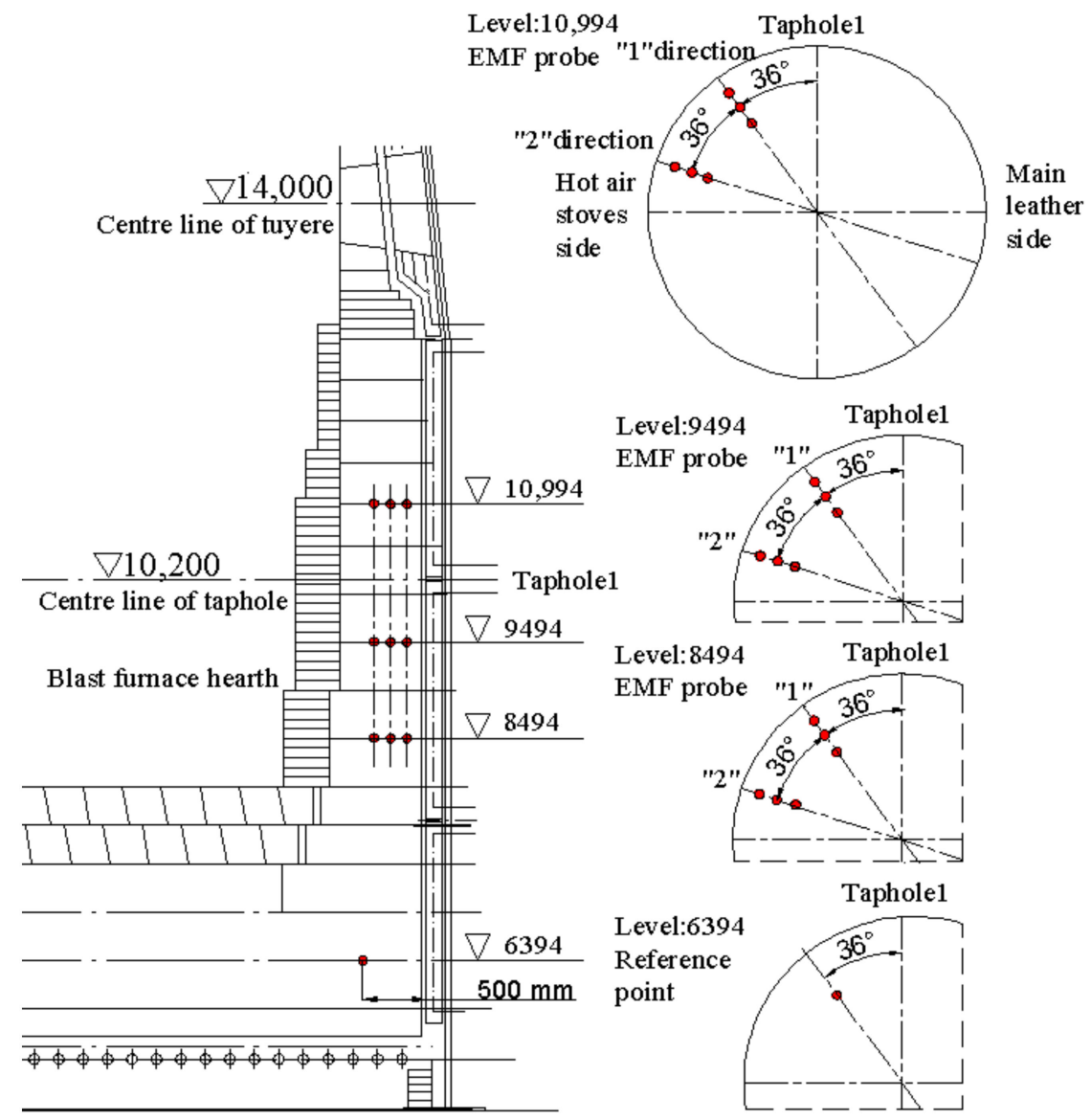

Figure 7. EMF sensors (signals) on the refractory wall of a new blast furnace hearth (left: front view of EMF locations at level 6394, 8494, 9494, and 10,994, right: top view of EMF locations in each levels).

The above installation of the EMF hardware was completed during the construction of the blast furnace. After the blast furnace was blown in for 3 months to achieve stable operation and the desired design production capacity, the experiments were conducted in 3 days.

\section{Results and Discussion}

\subsection{Laboratory Scale Experiments}

In order to analyze the relationship between EMF signals and refractory thickness, three laboratory experiments were designed. Figure 8a shows the EMF signals of the three heights of the arcs in the bottom of the crucible during the draining process of the molten tin. Because the contact surface between the arc and the inner wall of the vessel was fragile, EMF increased weakly with the increases of the heights of the arcs after $10 \mathrm{~s}$, and there was no good correlation with the segment level of arc, especially during the first $10 \mathrm{~s}$.

Another laboratory experiment was performed on a new vessel, which had four different thicknesses $(5,10,15$, and $20 \mathrm{~mm})$ at different points along the circumference. The results are shown in Figure $8 \mathrm{~b}$. With an increase in the wall's thickness, the EMF decreased, especially after $9 \mathrm{~s}$. This indicated that the EMF signals had a good correlation with the thickness of the wall. Furthermore, the differences in EMF $(\triangle \mathrm{EMF})$ were almost equal among the different thicknesses of the wall. 
The third way to study the relationship between the thickness of the refractory material and the EMF signal was to use the EMF sensors that were fixed at five depths $(24,19,14,9$, and $4 \mathrm{~mm})$ in a hole on the wall of the vessel. These results are presented in Figure 8c, where the $\mathrm{X}$-axis (time of molten tin drainage) $=0$ and the end of the $\mathrm{X}$-axis indicates the start and end of the drainage in the vessel. The EMF signals increased with an increase in the depth of the hole, and the difference in $\triangle \mathrm{EMF}$ signals was almost equal, especially in the interval of 0 to $6 \mathrm{~s}$ shown in Figure $8 \mathrm{c}$. The above indicates EMF signals had a positive relationship with the thickness of the refractory wall.

From the above analysis, EMF signal magnitude can be used to represent the thickness of crucible walls. Therefore, industrial scale experiments were planned on torpedo ladles and blast furnaces, which are described in the next section.
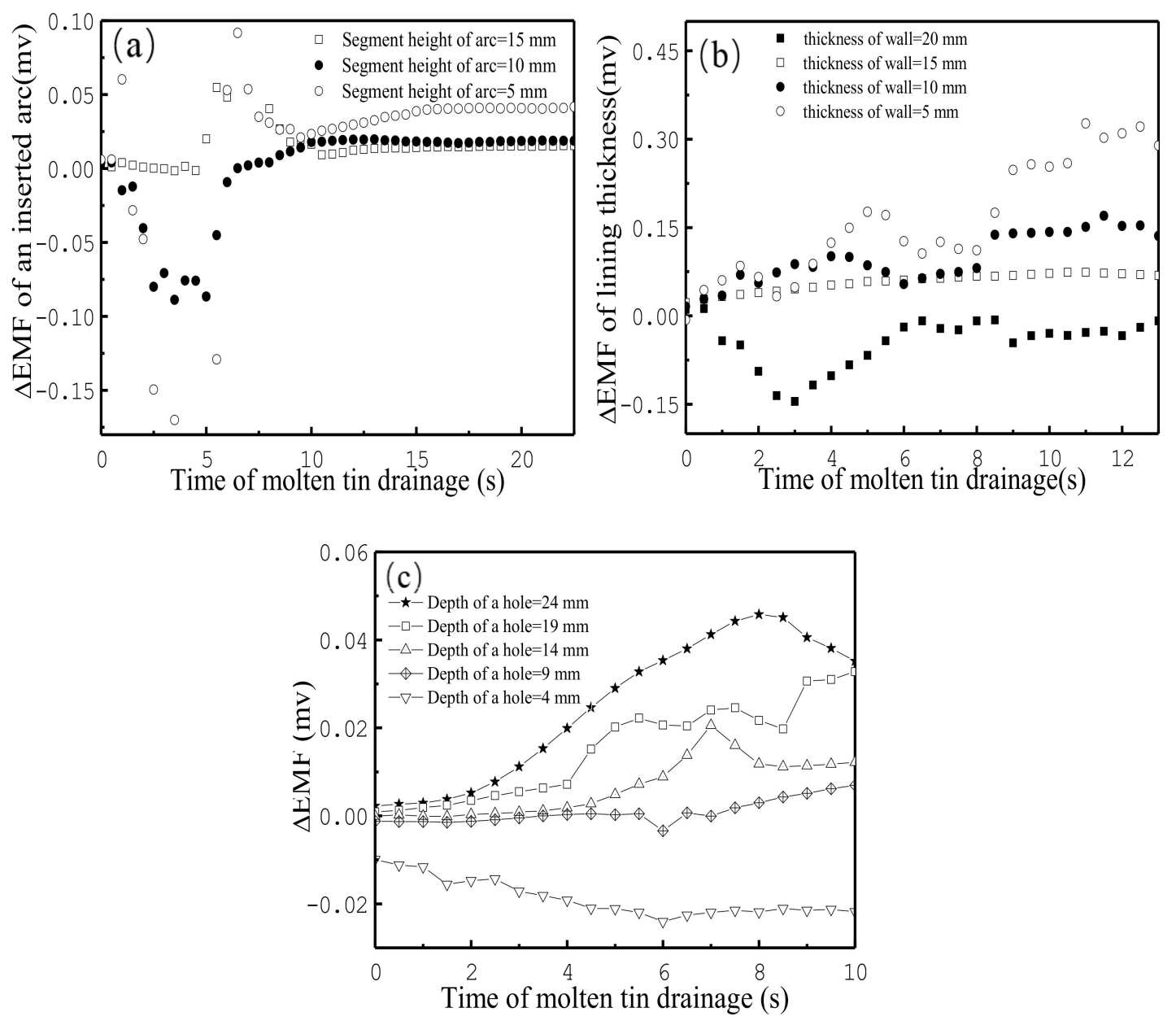

Figure 8. Results of three different scenarios: (a) three arc inserts; (b) four different thicknesses along the circumference; and (c) five depths in a hole in the wall of the vessel: 24, 19, 14, 9, and $4 \mathrm{~mm}$.

\subsection{Industrial Torpedo Ladle Experiments}

Torpedo ladle measurement experiments were conducted under the casting house of a blast furnace in Baosteel. Figure 9 shows the $\triangle E M F$ signals collected from the "a" location during a time period. The EMF signals were collected with the aforementioned receiving procedure of the liquid metal, which showed an increasing tendency over time. Furthermore, $\triangle E M F$ at a depth of $44 \mathrm{~mm}$ is greater than at a depth of $32 \mathrm{~mm}$, which is consistent with the results obtained from the laboratory vessel. 


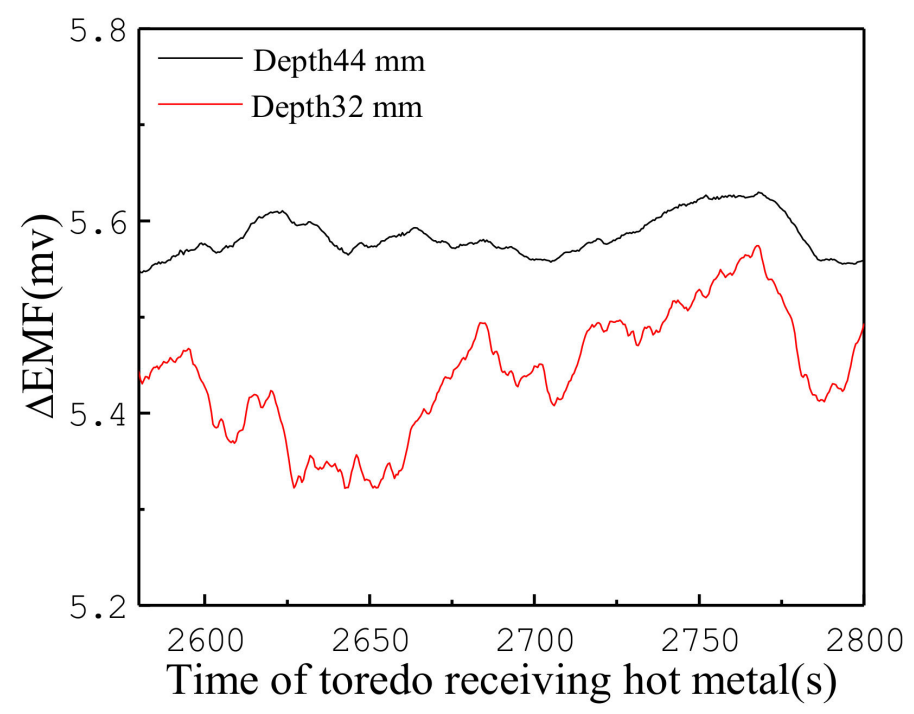

Figure 9. EMF signals on the torpedo ladle refractory wall in a short time interval.

According to Fourier's law of heat conduction $[20,26]$, the refractory thickness of each layer is calculated by EMF, listed in Table 1. The thickness of each layer has the same value as displayed in Figure 4B, except for the $\mathrm{Al}_{2} \mathrm{O}_{3}-\mathrm{SiC}-\mathrm{C}$ (ASC) brick. The ASC brick had a thickness of $130.35 \mathrm{~mm}$ from EMF calculation, and it was $140 \mathrm{~mm}$ from the engineer's measurement. Both values were almost half that of the design value $(260 \mathrm{~mm})$. Furthermore, the relative error of EMF was only $6.8 \%$.

Table 1. Results of torpedo ladle thickness (t1 to t6 reference to Figure 4B).

\begin{tabular}{lcccccc}
\hline Locations & $\begin{array}{c}\text { Hot Metal } \\
(\mathbf{t} 1)\end{array}$ & $\begin{array}{c}\text { ASC Brick } \\
(\mathbf{t} 2)\end{array}$ & $\begin{array}{c}\text { Ramming } \\
\text { Material (t3) }\end{array}$ & $\begin{array}{c}\text { Pyrophyllite } \\
\text { Brick (t4) }\end{array}$ & Shell (t5) & Shell (t6) \\
\hline $\begin{array}{l}\text { Thickness } \\
(\mathrm{mm})\end{array}$ & - & $\begin{array}{c}130.35 \\
(140 * *)\end{array}$ & 40.00 & 35.00 & 35.00 & 32.00 \\
\hline $\begin{array}{l}\text { Temperature } \\
\text { at t1-t6 }\left({ }^{\circ} \mathrm{C}\right)\end{array}$ & $1150 *$ & 1054.39 & 819.69 & 477.41 & 135.14 & 131.22 \\
\hline EMF at t1-t6 & 46.99 & 43.5 & 34.09 & 19.5 & 5.5 & 5.34 \\
\hline heat flux (J/s) & - & 5867.60 & 5867.60 & 5867.60 & 5867.60 & 5867.60 \\
\hline $\begin{array}{l}\text { where * expresses solidification temperature of hot metal }=1150^{\circ} \mathrm{C} \text { and } \\
\text { plant engineers. }\end{array}$
\end{tabular}

\subsection{Industrial Blast Furnace Hearth Experiments}

In order to further study EMF monitoring technology, a 3-day monitoring experiment was carried out on a newly constructed blast furnace. EMF signals on the blast furnace included the basic, the periodic, and the noise part [27]. The noise should be removed. When the blast furnace operation was stable, the EMF value fluctuated in a period, as shown in the normal noise in Figure 10a. Moreover, when there were disturbances, the amplitude of the EMF signal decreased, which can be seen by the special noise shown in Figure 10a. The removal method of the noise signals is further explained in our previous work [28]. 

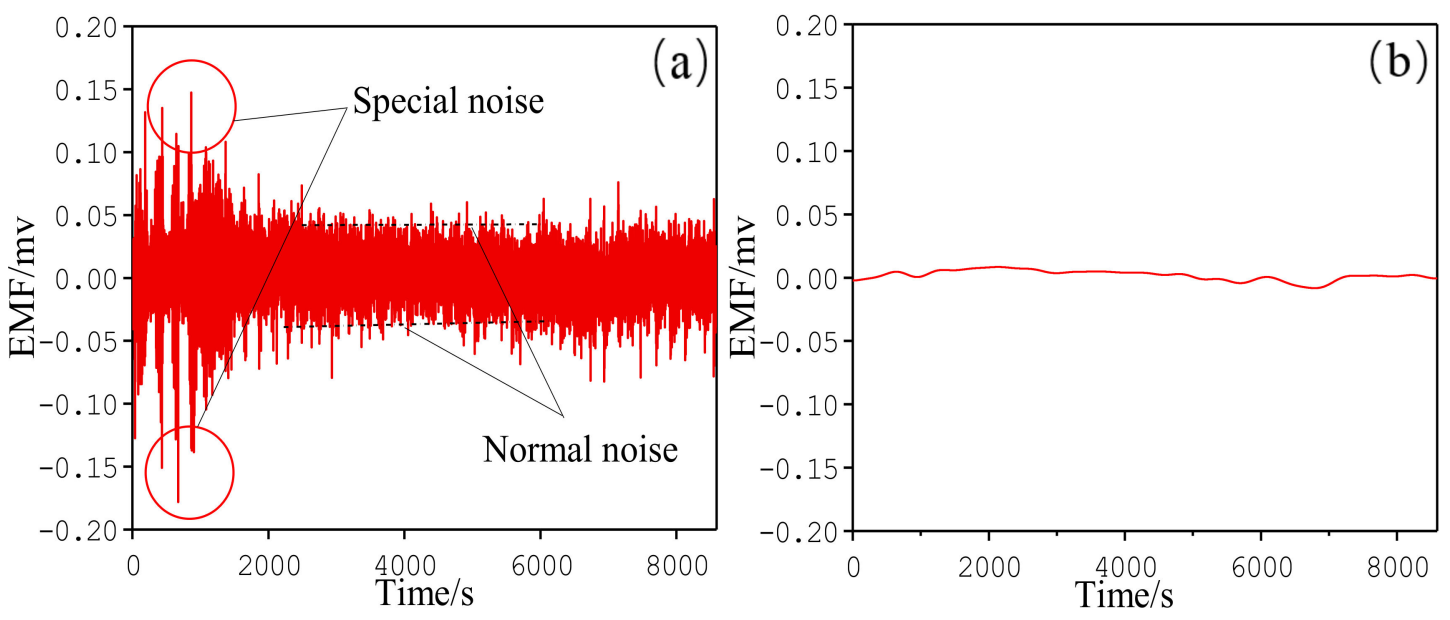

Figure 10. EMF signal: (a) original signal and (b) processed signal.

The thickness of the hearth wall can be seen in Table 2. According to the installation points of the EMF sensors and the structure of the blast furnace, the EMF measurement principle [29-31] of the blast furnace is drawn in Figure 11 and the equivalent circuit of EMF signals is illustrated in Figure 12. The EMF signal gradually decreased with increasing tapping time. During the tapping gap, the EMF signal strengthened as the liquid iron level in the hearth increased. The absolute value of EMF at $200 \mathrm{~mm}$ depth was greater than at $100 \mathrm{~mm}$ depth at 8494 and 9494 levels, indicating that EMF increased with the decrease in the refractory thickness. More details of the studies on the effects of liquid levels with EMF can be found in our previous work [28].

In summary, the change in EMF signal was consistent with the previous laboratory and torpedo ladle experiment. Average values of EMF signals at an 8494 level were $0.0082 \mathrm{mv}$ at a $100 \mathrm{~mm}$ depth and $0.019 \mathrm{mv}$ at a $200 \mathrm{~mm}$ depth, and $0.047 \mathrm{mv}$ at a $100 \mathrm{~mm}$ depth and $0.061 \mathrm{mv}$ at a $200 \mathrm{~mm}$ depth at a 9494 level.

Table 2. Refractory material properties of the hearth as shown in Figure 7.

\begin{tabular}{cccc}
\hline Materials & Ceramics Tiles & Ramming Material & Graphite Brick \\
\hline Thickness at level 8494 $(\mathrm{mm})$ & 860 & 10 & 560 \\
\hline Resistivity $(\Omega \cdot \mathrm{mm})$ & $2.63 \times 10^{-8}$ & 0.8 & 0.577 \\
\hline Thickness at level $9494(\mathrm{~mm})$ & 730 & 10 & 560 \\
\hline Resistivity $(\Omega \cdot \mathrm{mm})$ & $2.63 \times 10^{-8}$ & 0.8 & 0.577 \\
\hline
\end{tabular}

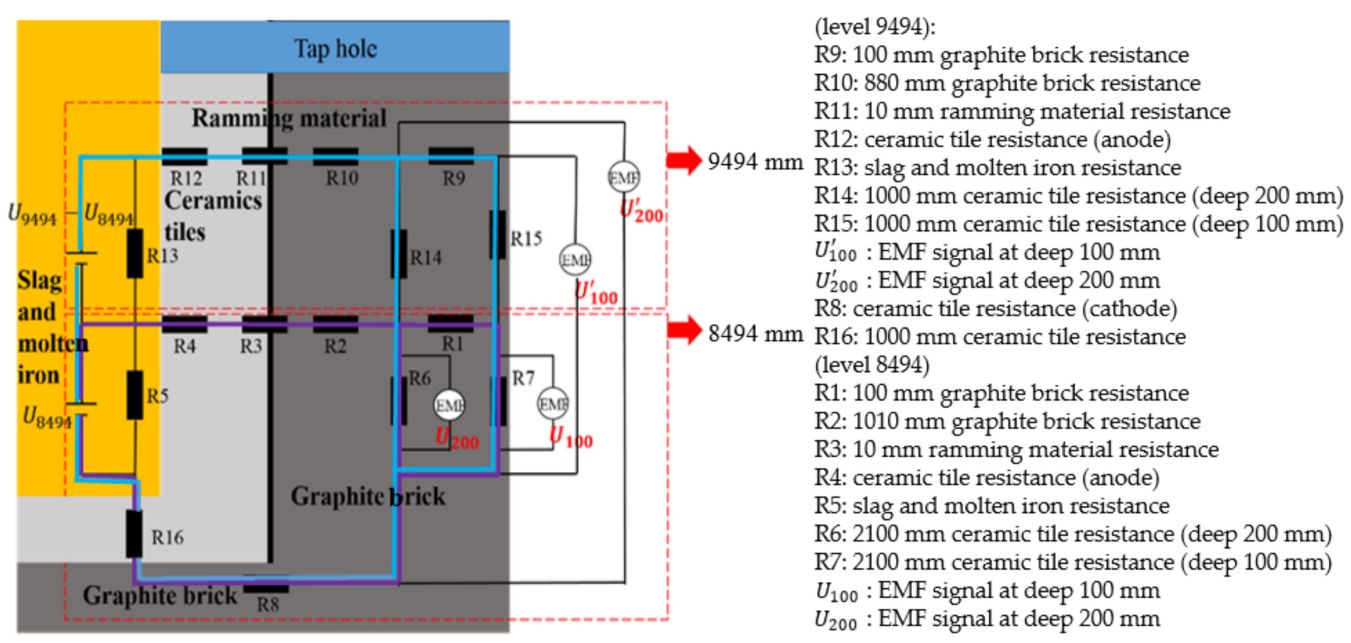

Figure 11. EMF measurement principles of the blast furnace. 

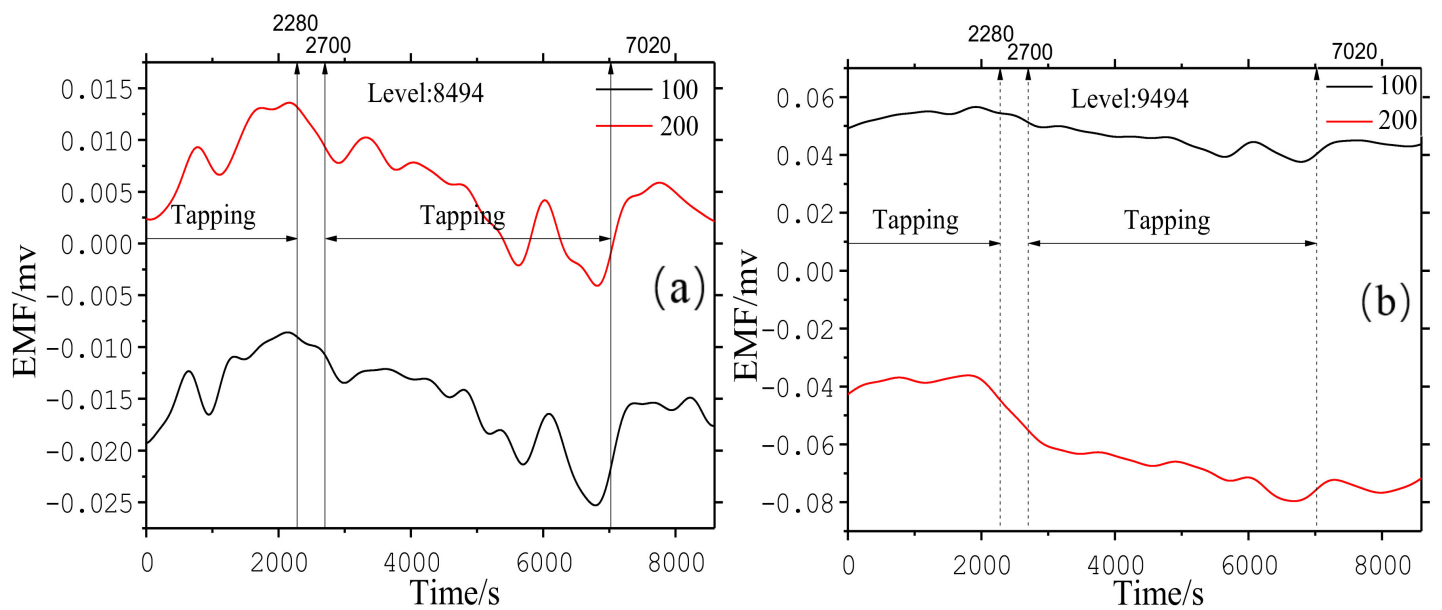

Figure 12. EMF signals of blast furnace hearths: (a) EMF signals on the " 2 " direction at the 8494 level and (b) EMF signal on the "2" direction (C.F. Figure 7) at the 9494 level.

The calculation of refractory thickness for the 9494 level of blast furnace is described in the following texts:

(1) With regard to the purple loop, Ohm's and resistance's law are displayed in Figure 11. Equations (3) and (4) can calculate EMF of the slag-iron liquid at level 8494.

$$
\begin{gathered}
\left(\frac{U_{200}}{R 6}+\frac{U_{100}}{R 7}\right) \times(R 2+R 3+R 4+R 8+R 16)+U_{200}=U_{8494} \\
R_{i}=\frac{\rho_{i} L_{i}}{S}
\end{gathered}
$$

where $R_{i}$ defines the resistance of the ith material in Figure 11, and $L_{i}$ and $S$ express the thickness of the ith material in Figure 11 and the cross-sectional area of the current flow, respectively.

(2) The tapping gap between two serial tapping times was very short. Therefore, the liquid level of the hearth could not drop below $9494 \mathrm{~mm}$, under which molten iron and slag exist. As the distance between the EMF sensors at $8494 \mathrm{~mm}$ and the one at the bottom of the hearth was $500 \mathrm{~mm}$, and the distance between the 9494 level and the one at the bottom was $1500 \mathrm{~mm}$, the relationship of Equation (5) was satisfied. A relationship of slag-iron liquid between the 8494 level and 9494 level could then be made:

$$
U_{9494}=3 U_{8494}
$$

(3) According to the blue loop in Figure 11, the remaining thickness of the refractory material at the 9494 level was predicted by

$$
\left(\frac{U_{200}^{\prime}}{R 6+R 14}+\frac{U_{100}^{\prime}}{R 7+R 15}\right) \times(R 10+R 11+R 12+R 8+R 16)+U_{200}^{\prime}=U_{9494}
$$

According to Equations (3)-(6), the thickness of refractory walls at the $9494 \mathrm{~mm}$ level was calculated:

$$
b=\frac{R 12}{\rho 12}=502.3 \mathrm{~mm}
$$

where $\rho 12$ is the same as $\rho 12$ and the design thickness is $560 \mathrm{~mm}$.

The relative error of the thickness between the EMF calculation (502.3) and design value (560) was $10.3 \%$. This error was in the allowable range, thus it can be accepted that the relative error of the refractory thickness in the " 1 " direction is around $12.1 \%$. Therefore, EMF measurement is a suitable method for detecting the thickness of blast furnace hearth walls. 


\section{Conclusions}

The use of metallurgical vessels, such as blast furnaces, shaft furnaces, and torpedo ladles, can be better controlled and expanded for a longer lifespan, if the thickness of the refractory lining wear is known and predicted reliably. This work presents a novel method to study refractory lining wear in metallurgical vessels by focusing on the measurement of the EMF signal relationship with the thickness of refractory walls on a small-scale vessel, an industrial torpedo ladle, and a new blast furnace hearth. The main objectives of this study were to observe the correlation between wall thickness and EMF signals from four different types of wall structures. The main conclusions can be drawn as follows.

1. An EMF approach was built and used to measure the thickness of refractory walls in laboratory scale vessels, industrial scale torpedo ladles, and a new blast furnace hearth;

2. The thickness of refractory walls increased with the decrease in EMF signal magnitude;

3. The comparison of wall thickness obtained by EMF and engineering measurement from a plant showed that EMF could measure the thickness of torpedo ladles with a relative accuracy of $6.8 \%$;

4. For the industrial blast furnace application, it was proven that the EMF is accurate for measuring hearth wall thickness, and the relative error is less than $11 \%$.

Author Contributions: Data curation \& formal analysis, W.D. and H.N.; investigation \& validation, Y.L.; review \& supervision, Y.Y.; investigation \& validation, Y.C.; writing-original draft, Y.G.; writing—review \& editing \& investigation, H.W. All authors have read and agreed to the published version of the manuscript.

Funding: This research was funded by The Program for Professor of Special Appointment (Eastern Scholar) at Shanghai Institutions of Higher Learning and grant number TP2015039, National Natural Science Foundation of China, grant number 51974182 and National 111 project, Grant/Award number 17002.

Conflicts of Interest: The authors declare no conflict of interest.

\section{References}

1. Zhang, M.J.; Ni, K.X.; Gu, H.Z.; Xia, Q.L.; Li, G.Q.; Yu, C. Mullite-silicon carbide refractory materials strengthened by in-situ generated AIN crystal whiskers for dry quenching coke furnace. Refractories 2019, 53, 247-253. [CrossRef]

2. Biswas, S. Novel Silica Refractory for Small Sized Steel Ladles. In Proceedings of the 118th Metalcasting Congress, Schaumburg, IL, USA, 18-21 April 2014; pp. 14-26.

3. Zhu, T.; Li, Y.; Sang, S.; Xie, Z. Mechanical behavior and thermal shock resistance of MgO-C refractories: Influence of graphite content. Ceram. Int. 2017, 43, 7177-7183. [CrossRef]

4. Pilli, V.; Sarkar, R. Nanocarbon containing $\mathrm{Al}_{2} \mathrm{O}_{3}-\mathrm{C}$ continuous casting refractories: Effect of graphite content. J. Alloy. Compd. 2017, 735, 1730-1736. [CrossRef]

5. Liang, L.H.; Ge, Q. Discussion on Selection of the Refractory Material of Blast Furnace. Taiyuan Sci. Technol. 2004, 5, 66-67.

6. Jiao, K.X.; Zhang, J.L.; Liu, Z.J.; Chen, C.L.; Liu, Y.X. Analysis of Blast Furnace Hearth Sidewall Erosion and Protective Layer Formation. ISIJ Int. 2016, 56, 1956-1963. [CrossRef]

7. Justus, S.M.; Wen, H.Q. Explore the corrosion mechanism of refractory materials to save the cost of steel production. World Iron Steel 2002, 2, 39-44.

8. Silva, S.N.; Vernilli, F.; Justus, S.M.; Marques, O.R.; Mazine, A.; Baldo, J.B.; Longo, E.; Varela, J.A. Wear mechanism for blast furnace hearth refractory lining. Ironmak Steelmak 2013, 32, 459-467. [CrossRef]

9. Chen, L.Y.; Wang, C.S. Multi-dimensional diagnosis and structural safety assessment of blast furnace hearth erosion. In Proceedings of the 2014 Technical Exchange Conference on Energy Conservation and Longevity of Iron and Steel Metallurgical Equipment and Industrial Furnaces, Shandong, China, 16 July 2014; pp. 34-41.

10. Sadri, A.; Filatov, S.; Kurunov, I.; Gordon, Y.; Ying, W.L.; Erskine, J. Monitoring and control of refractory wear for intensive operation of blast furnace. In Proceedings of the $71^{\circ}$ Congresso Anual Da Abm, Rio de Janeiro, Brazil, 26-30 September 2016; pp. 191-201.

11. Bolf, N. Application of infrared thermography in chemical engineering. J. Chem. Chem. Eng. 2004, 53, 549-555. 
12. Salgado, J.; Oliveira, C.; Moutinho, A.; Silvério, C. Control of refractory lining wear by using radioisotopes. Int. J. Radiat. Appl. Instrum. Part A Appl. Radiat. Isot. 1988, 39, 1265-1267. [CrossRef]

13. Staicu, L.; Radu, R. The use of the $(\gamma, \mathrm{n})$ reaction to measure wear in blast furnaces and other industrial furnaces: Comparison with present methods. J. Phys. D 1983, 16, 2541. [CrossRef]

14. Parker, R.L.; Manning, J.R. Application of pulse-echo ultrasonics to locate the solid/liquid interface during solidification and melting. J. Cryst. Growth 1986, 79, 341-353. [CrossRef]

15. Sadri, A.; Gebski, P. Non-destructive testing (NDT) and inspection of the blast furnace refractory lining by stress wave propagation technique. In Proceedings of the 5th International Congress on the Science and Technology of Ironmaking, Shanghai, China, 10 October 2009; pp. 955-959.

16. Sadri, A.; Ying, W.; Gebski, P.; Szyplinski, P.; Goff, T.; van Beek, B. A comprehensive review of acousto ultrasonic-echo (AU-E) technique for furnace refractory lining assessment. In Proceedings of the 54th Annual Conference of Metallurgists, Toronto, ON, Canada, 23-26 August 2015.

17. Zhao, H.B.; Cheng, S.S. Optimization for the structure of BF hearth bottom and the arrangement of thermal couples. J. Univ. Sci. Technol. Beijing 2006, 13, 497-503. [CrossRef]

18. Zhao, H.B.; Cheng, S.S.; Huo, S.F. Online Working Status Measurement of BF Cooling Stave, hearth and bottom. Ironmaking 2008, 27, 18-22. [CrossRef]

19. Sadri, A.; Ying, W.L.; Erskine, J.; Macrosty, R. Smelting Furnace Non Destructive Testing (NDT) and Monitoring. In Proceedings of the 19th World Conference on Non-Destructive Testing 2016, Munich, Germany, 13-17 June 2016; pp. 56-67.

20. Torrkulla, J.; Saxen, H. Model of the State of the Blast Furnace Hearth. ISIJ Int. 2000, 40, 438-447. [CrossRef]

21. Kouji, T.; Takanobu, I.; Kouzo, T. Mathematical Model for Transient Erosion Process of Blast Furnace Hearth. ISIJ Int. 2007, 41, 1139-1145. [CrossRef]

22. Zagaria, M.; Dimastromatteo, V.; Colla, V. Monitoring erosion and skull profile in blast furnace hearth. Ironmak Steelmak 2010, 37, 229-234. [CrossRef]

23. Swartling, M.; Sundelin, B.; Tilliander, A.; Jnsson, P. Short-term Lining Temperature Changes during Tapping in a Blast Furnace. Steel Res. Int. 2010, 81, 724-734. [CrossRef]

24. Guo, B.Y.; Maldonado, D.; Zulli, P.; Yu, A.-B. Cfd Modelling of Liquid Metal Flow and Heat Transfer in Blast Furnace Hearth. ISIJ Int. 2008, 48, 1676-1685. [CrossRef]

25. Hattink, M.; van der Stel, J.; Lecacheux, B. Determination of Factors Influencing the Deadman Position and Evaluation of Its Impact on Blast Furnace Lifetime; Research Fund for Coal and Steel-Publications Office of the European Union: Luxembourg, 2011; pp. 21-37.

26. Du, G.; Chen, L. Two dimensional model of thermal conduction for the hearth and bottom of the blast furnace. Refractories 1999, 33, 216-218.

27. Gomes, F.S.V.; Salles, J.; Wasem, L. A new prediction model for liquid level in blast furnaces based on time series analysis. In Proceedings of the 9th IEEE International Conference on Control and Automation, Santiago, Chile, 19-21 December 2011.

28. Ge, Y.; Tang, X.J.; Li, M.; Wei, H.; Bi, C.G.; Lu, K.C.; Yu, Y.W. Electromotive force method for measuring liquid level in a container. China Metall. 2020, 30, 6-12. [CrossRef]

29. Ito, T.; Yotsuji, J.; Nagamune, A. Development of pig iron and molten slag level measurement technique for blast furnace. ISIJ Int. 2014, 54, 2618-2622. [CrossRef]

30. Pei, Z.Y.; Lin, Y.G. Research on Monitoring Method of Blast Furnace Hearth. Shougang Technol. 1993, 1, 1-5.

31. Alter, M.A.; Brunner, J.M.; Holmes, D.J. Continuous monitoring of liquid level and thermal state in the hearth based on measurement of EMF on the blast furnace shell. Iron Steel Technol. 2013, 10, 43-50.

Publisher's Note: MDPI stays neutral with regard to jurisdictional claims in published maps and institutional affiliations. 